\title{
INTERVENÇÃO DO ENFERMEIRO DE REABILITAÇÃO NO GANHO DE EQUILÍBRIO POSTURAL NA PESSOA APÓS ACIDENTE VASCULAR CEREBRAL: ESTUdo dE CASO
}

\author{
INTERVENCIÓN DE LA ENFERMERA DE REHABILITACIÓN EN LA GANANCIA DE EQUILIBRIO \\ EN PERSONA CON ACCIDENTE CEREBROVASCULAR: ESTUDIO DE CASO
}

\section{Rehabilitation Nurse Intervention in Postural Balance Gain in Person After Stroke: Case Study}

DOI 10.33194/rper.2020.v3.s1.1.5755 | Submetido 20/12/2019 | Aprovado 26/10/2020

\begin{abstract}
Inês De Jesus Rocha' ${ }^{1}$; Maria Félix Martin Bravo² ${ }^{\mathbb{D}}$; Luís Manuel Mota Sousa ${ }^{3,4}(\mathbb{D}$; Ana Cristina Nunes Mesquita ${ }^{5} \mathbb{D}$; Helena Castelão Figueira Carlos Pestana ${ }^{5} \mathbb{D}$
\end{abstract}

\author{
1 - Centro Hospitalar Lisboa Central - Hospital Curry Cabral; 2 - Hospital Santa Maria; \\ 3 - Universidade de Évora; 4 - Comprehensive Health Research Centre; 5 - Escola Superior de Saúde Atlântica
}

\section{RESUMO}

Introdução: A pessoa com Acidente Vascular Cerebral (AVC) pode apresentar perda do controlo da mobilidade do tronco, o que pode conduzir a um comprometimento no equilíbrio e da postura corporal e consequentemente um défice no desempenho das atividades motoras para a recuperação da marcha e reaquisição da independência funcional.

Objetivo: Identificar os ganhos sensíveis aos cuidados de enfermagem de reabilitação com um programa de atividades e exercícios terapêuticos na recuperação do equilíbrio postural na pessoa com AVC.

Método: Estudo de abordagem qualitativa, tipo estudo de caso. É apresentado o caso de uma pessoa idosa com alteração do equilíbrio, admitida no serviço de neurologia. Os princípios éticos em investigação foram cumpridos.

Resultados: Foram evidenciados ganhos na força muscular, no equilíbrio postural e na funcionalidade após implementação de 10 sessões de exercícios terapêuticos e treino de equilíbrio.

Conclusão: A sistematização dos cuidados de enfermagem de reabilitação revelou-se capaz de melhorar a recuperação do equilíbrio corporal na pessoa com AVC isquémico, maximizando a sua funcionalidade.

Palavras-chave: Equilíbrio postural, Acidente Vascular Cerebral, Enfermagem de Reabilitação, Exercícios Terapêuticos

\section{RESUMEN}

Introducción: Una persona con accidente cerebrovascular puede tener una pérdida de control de la movilidad del tronco, lo que puede conducir a un deterioro del equilibrio y la postura corporal y, en consecuencia, problemas de motricidad para la recuperación y recuperación de la marcha de independencia funcional.

Objetivo: Identificar ganancias sensibles en la atención de enfermera de rehabilitación con un programa de actividades y ejercicios terapéuticos en la recuperación del equilibrio postural en pacientes con accidente cerebrovascular.

Método: Estudio de enfoque cualitativo, tipo de estudio de caso. Presentamos el caso de una persona mayor con equilibrio alterado, ingresada en el departamento de neurología. Se han cumplido los principios éticos en la investigación.

Resultados: Se evidenciaron ganancias en la fuerza muscular, el equilibrio postural y la funcionalidad después de la implementación de 10 sesiones de ejercicios terapéuticos y entrenamiento de equilibrio.

Conclusiones: Se ha demostrado que la sistematización de los cuidados de rehabilitación de enfermería mejora la recuperación del equilibrio corporal en personas con accidente cerebrovascular isquémico, maximizando su funcionalidad.

Palabras clave: Equilibrio postural, accidente cerebrovascular, enfermera de rehabilitación, ejercicio terapéutico

\section{ABSTRACT}

Background: A person with stroke may have a loss of control of trunk mobility, which may lead to impaired balance and body posture and, consequently, impaired motor skills for gait recovery and recovery of functional independence.

Objective: To identify sensitive gains in rehabilitation nursing care with a program of activities and therapeutic exercises in the recovery of postural balance in stroke patients. 
Method: Qualitative approach study, case study type. We present the case of an elderly person with altered balance, admitted to the neurology department. The ethical principles in research have been fulfilled.

Results: Gains in muscle strength, postural balance and functionality were evidenced after 10 sessions of therapeutic exercises and balance training.

Conclusions: The systematization of rehabilitation nursing care has been shown to improve body balance recovery in people with ischemic stroke, maximizing its functionality.

Keywords: Postural balance, Stroke, Rehabilitation Nursing, Therapeutic Exercise

\section{INTRODUÇÃO}

As doenças cardiovasculares são a principal causa de morte a nível mundial assim como uma das mais importantes causas de morbilidade, de incapacidade, invalidez e de anos potenciais de vida precocemente perdidos. Englobada nas doenças cardiovasculares, a doença isquémica cardíaca e as doenças cerebrovasculares correspondem a $60 \%$ de todas as causas de morte cardiovasculares na união europeia ${ }^{(1)}$. E dados de 2017 revelam que apesar da diminuição da taxa de mortalidade na última década por doenças do aparelho circulatório, ainda representam a principal causa de morte no país $(29,3 \%)$. Do leque destas doenças, o AVC é a principal causa, seguida da doença isquémica do coração ${ }^{(2-3)}$.

Todavia, com a implementação de programas e estratégias preventivas adotadas ao nível nacional verifica-se uma grande redução de mortalidade ocorrida nas doenças cerebrovasculares $(19,7 \%)$ e em particular no AVC isquémico, em idades inferiores a 70 anos. E este valor deve-se em parte pela introdução na prática clínica de novos fármacos e técnicas inovadoras e efetivas assim como pelo correto encaminhamento dos casos de AVC, através da ativação da via verde, que traduz um ganho de tempo fundamental para a efetividade da terapêutica e dos tratamentos ${ }^{(1,4-5)}$.

O AVC é caracterizado pela interrupção ou bloqueio da irrigação sanguínea, levando a um enfarte (AVC isquémico) ou a uma hemorragia (AVC hemorrágico) no parênquima cerebral que o danifica ou destrói. Através dos sinais clínicos, de início súbito, de distúrbios focais da função cerebral, origina um conjunto de sintomas de défice neurológico que perduram por um período que ultrapassa as 24 horas $^{(6)}$.

A maioria das pessoas sobreviventes de AVC geralmente apresentam défices neurológicos e incapacidades residuais significativas ao nível físico, sensorial, cognitivo, de linguagem e visuais a longo prazo, que podem conduzir a uma diminuição da capacidade funcional em realizar várias AVD, como vestir-se, alimentar-se e caminhar, entre outras ${ }^{(7-8)}$.

Conhecida como uma das principais causas de incapacidade na pessoa adulta, espera-se que deste advento $60 \%$ das pessoas recuperem a independência para os autocuidados, $75 \%$ recuperem a independência para a marcha e $20 \%$ necessitem de cuidados institucionais ${ }^{(7-8)}$.

À luz da evolução das neurociências e da tecnologia, existe um aumento da esperança média de vida das pessoas com alterações neurológicas e algumas destas patologias assumem um caracter crónico pelo que é fundamental a otimização dos recursos existentes e da gestão dos cuidados tendo em vista a melhor recuperação ao menor custo socioeconómico e familiar ${ }^{(4-5)}$.

Para além dos défices já referidos, a perda do controlo da mobilidade do tronco é uma das perturbações mais importantes, uma vez que todas as atividades funcionais normais dependem do controlo de tronco como base para o movimento. A função dos músculos do tronco é um fator essencial para o equilíbrio, transferências, marcha e entre outras funções.

O equilíbrio corporal permite a manutenção da postura corporal com um mínimo de oscilação ou a manutenção da postura durante o desempenho de uma atividade motora que tende a perturbar a orientação do corpo ${ }^{(8)}$.

Neste sentido, para ocorrer a independência nas AVD é necessário existir um desempenho satisfatório de diversos movimentos, como por exemplo levantar-se de uma cadeira ou deambular. Sabe-se que o domínio do controlo postural (seja a orientação postural, a manutenção da posição dos segmentos corporais em relação ao próprio corpo/ambiente e o equilíbrio postural) é solicitado na execução destas atividades de forma automática, no entanto, quando ocorre um AVC aumenta a probabilidade de diminuição da capacidade de equilíbrio ${ }^{(8)}$.

A hemiplegia é uma sequela comum do AVC e é comummente associada a uma diminuição na capacidade de equilíbrio. A oscilação postural é duas vezes maior nas pessoas com AVC o que conduz à diminuição dos limites de estabilidade, nomeadamente na sua capacidade de se levantar ou andar (por limites de estabilidade considera-se a distância máxima que uma pessoa pode mudar seu peso em qualquer direção sem perder o equilíbrio) ${ }^{(9)}$.

Nesta perspetiva, para melhorar a capacidade de equilíbrio, a pessoa tem que aumentar a estabilidade do tronco. Esta é necessária para manter o equilíbrio da coluna vertebral e da pélvis quando estão numa posição funcional e assim obter o autocontrolo durante o movimento e força muscular para ajustar os movimentos e equilíbrio musculares ${ }^{(9)}$.

Assim é fundamental a implementação de um programa de reabilitação onde sejam realizados exercícios de ativação de tronco na promoção do equilíbrio já que a fraqueza do tronco é relevante para o desempenho funcional das pessoas com AVC.

As atividades e exercícios terapêuticos devem ser desenvolvidos de forma gradual, iniciando-se com mobilizações, evoluindo para atividades terapêuticas 
com o objetivo de readquirir uma postura adequada do corpo até à obtenção da posição ereta. Desta forma devem-se iniciar exercícios como rolar e levantar, ponte, treino de equilíbrio sentado e de pé estático e dinâmico ${ }^{(9)}$.

Para Song e colaboradores, os principais exercícios de estabilização do tronco focam-se na inclinação pélvica, exercícios de "quadrúpedes bird-dog" (exercícios de estabilização e fortalecimento da coluna), de contração abdominal e de ponte, pois promovem a coordenação da posição sentada para a posição ortostática ${ }^{(9)}$.

Os exercícios de ponte, ativam a musculatura do tronco, estimulam a sensibilidade postural e a mudança de posição no leito. Através da estabilização lombo pélvica, reduz-se o centro de gravidade da pessoa, reduz-se o medo e a instabilidade do peso durante a marcha e permite-se que o exercício se realize numa postura segura ${ }^{(9-10)}$.

Diferentes estudos têm sido desenvolvidos na área de reabilitação nomeadamente na aquisição do equilíbrio em pessoas com AVC. Song e colaboradores submeteram pessoas com hemiplegia a realizar exercícios de ponte modificada com o objetivo de verificar a influência que este exercício apresenta na melhoria de suporte do peso no lado afetado e na capacidade de equilíbrio estático e dinâmico de pé(9).

Pela comparação de exercícios de ponte supina, com exercícios de ponte supina sobre almofadas de equilíbrio (almofadas que promovem estímulos regulados usados para a estabilização muscular, tendões, ligamentos, sem sobrecarga sensorial) e ainda exercícios de ponte supina unilateral, os resultados evidenciaram que os últimos dois exercícios foram mais eficazes. Ocorreu um aumento dos limites de estabilidade anterior e posterior tal como a melhoria da sustentação do peso em pé e consequente melhoria do equilíbrio global nas pessoas com $\operatorname{AVC}^{(9)}$.

Fujino e colaboradores referem que o desempenho de tronco é um importante indicador do resultado funcional após AVC pelo que o ganho da capacidade de sentar torna-se um dos fatores mais importantes para melhorar a independência nas AVD para as pessoas com AVC na fase aguda. Assim, no seu estudo verificaram que o controlo lateral do tronco numa plataforma basculante com inclinação a $10^{\circ}$ para o lado parético melhora o desempenho do tronco e os movimentos de alinhamento corporal do lado parético para o lado são, permitem uma maior recuperação do controlo do tronco do que a mesma prática numa plataforma nivelada. Estes resultados sugerem que existe potencial terapêutico para o controlo lateral do tronco na reabilitação da pessoa com AVC e que é importante numa fase aguda estabilizar e obter o controlo postural primeiramente do lado são(11).

Haruyama e colaboradores avaliaram a eficácia do treino da estabilidade do core (exercícios com efeito estabilizador dos segmentos musculares do complexo “lombar, pélvico e anca") na melhoria da função do tronco, equilíbrio de pé e mobilidade entre as pessoas que apresentaram hemiplegia após o AVC.
Os exercícios desenvolvidos consistiram em atividades como ponte, movimentos pélvicos (inclinação ânteroposterior, elevação lateral e rotação transversal) e movimentos pélvicos seletivos (o recrutamento dos músculos abdominal transverso e a manobra de tração abdominal). Como resultados do estudo, verificaram-se que o grupo experimental (que recebeu o programa de exercícios convencional e exercícios de estabilidade do core) obteve os melhores resultados, melhorando não apenas a função do tronco, mas também o equilíbrio e a mobilidade ${ }^{(12)}$.

Lupo e colaboradores investigaram os efeitos sobre as atividades de equilíbrio e adesão ao treino de exercícios da pessoa com AVC subagudo através de um programa de videojogo que simule o treino de equilíbrio. $E$ constataram que o grupo experimental que realizou exercícios de treino de equilíbrio baseados em atividades do dia-a-dia (simulados pelo videojogo), obteve uma melhoria significativa nas habilidades de equilíbrio ${ }^{(13)}$.

Por serem solicitadas tarefas do dia-a-dia (exercícios como flexão plantar, como se usassem saltos altos, agachamento, como se arrumassem objetos), permitiram maior adesão dos participantes, e pelo facto da existência de um sistema de biofeedback, os investigadores consideram que melhoram o mecanismo de neuroplasticidade das habilidades posturais e de equilíbrio em pessoas com AVC(13).

Abordagens de reabilitação com recurso a realidade virtual para o controlo postural têm sido usadas para melhorar a recuperação funcional. Treino que potencializa a atividade motora/habilidades motoras através de feedback aumentam o conhecimento de desempenho e resultados ${ }^{(13)}$.

Numa abordagem diferente, Louie e colaboradores recorreram à terapia com espelho que pretende promover a mudança neuroplástica no cérebro na recuperação motora em pessoas com hemiplegia após AVC. Para tal, posicionou um espelho no plano mediano sagital para a estimulação do membro inferior plégico, ocultando a imagem do membro afetado pelo reflexo do membro são. Concluíram que ao nível da velocidade da marcha, mobilidade e função motora, o grupo que realizou terapia pelo uso do espelho obteve melhores resultados, contudo ao nível do equilíbrio, o uso combinado de terapia convencional com a estimulação elétrica neuromuscular obteve melhores resultados que a terapia por espelho unilateral de forma isolada. Sugerem assim que este tipo de terapia seja usado como adjuvante ${ }^{(7)}$.

De acordo com os diferentes estudos, verifica-se que a alteração do equilíbrio nas pessoas com AVC é um fator que compromete a recuperação da capacidade funcional para realizar as AVD tal como a independência na marcha, com consequente risco aumentado de queda. Para tal torna-se essencial a implementação de um programa de reabilitação precoce de forma a melhorar a estabilidade postural e minimizar as alterações do equilíbrio, na promoção da independência ${ }^{(7)}$.

Com base na importância da estabilidade postural para a locomoção segura, é necessário avaliar quais as 
estratégias a utilizar para pessoas que sofreram uma lesão neurológica para conseguir a estabilidade estática e dinâmica em pé. A partir deste conhecimento, através da avaliação inicial, pode-se então planear estratégias de reabilitação para estas pessoas com o objetivo de melhorar sua independência e qualidade de vida ${ }^{(8)}$.

A reabilitação enquanto especialidade multidisciplinar integra nas suas equipas o enfermeiro especialista em enfermagem de reabilitação (EEER), este profissional agrega um "conjunto de conhecimentos $e$ procedimentos específicos que permite ajudar as pessoas com doenças agudas, crónicas ou com as sequelas a maximizar o seu potencial funcional $e$ independência. Os seus objetivos gerais são melhorar a função, promover a independência e a máxima satisfação da pessoa $e$, deste modo, preservar a autoestima" (14) e assim permitir o processo de transição que envolve a adaptação à situação de doença e dependência(5).

Perante o supracitado, o presente estudo centrou-se na implementação de um programa de reeducação funcional, composto por intervenções específicas do EEER junto de uma pessoa com o equilíbrio de tronco comprometido, de etiologia neurológica. Foram desenvolvidas estratégias devidamente fundamentadas no Processo de Enfermagem e no Padrão Documental dos Cuidados Especializados da Especialidade de Enfermagem de Reabilitação. ${ }^{(15)}$ Igualmente, o uso de instrumentos de avaliação apropriados permitiu estabelecer critérios que ajudaram a definir diagnósticos de enfermagem de reabilitação centrados nos focos comprometidos ("movimento muscular", "equilíbrio corporal", "transferir" e "andar"), conduzindo à avaliação dos resultados do programa.

Assim formulou-se a questão orientadora: "Qual $a$ efetividade da intervenção do enfermeiro de reabilitação na implementação de exercícios de treino de equilíbrio para a recuperação do equilíbrio na pessoa com AVC isquémico?".

Como objetivo geral pretende-se identificar os ganhos sensíveis à atuação do EEER, com a aplicação de um programa de atividades e exercícios terapêuticos na recuperação do equilíbrio postural na pessoa com AVC isquémico.

\section{MATERIAL E MÉTODOS}

Em enfermagem o estudo de caso como método de pesquisa, permite ao investigador estudar fenómenos individuais ou de grupo não evidentes, em contexto real, com o objetivo de explorar, descrever e explicar um evento com base no problema de investigação de forma a compreender claramente o fenómeno, recorrendo a múltiplas fontes de evidência ${ }^{(16)}$.

Indo de encontro ao supracitado e recorrendo aos referenciais de Yin e Stake, o presente estudo de caso encontra-se organizado pela Definição do problema; Definição do caso; Fundamentação teórica; Elaboração do protocolo de estudo; Colheita de dados; Análise e Discussão dos resultados ${ }^{(16)}$.
O estudo descreve o caso de uma pessoa com equilíbrio de tronco comprometido devido ao AVC isquémico e demonstra o programa de reeducação funcional de equilíbrio desenvolvido durante o seu internamento, evidenciando os resultados obtidos. A colheita de dados foi realizada através da anamnese e consulta do processo clínico.

O programa de reabilitação do equilíbrio decorreu durante os meses de março, abril e maio de 2019, desde a admissão no internamento até à alta clínica da pessoa. Foram monitorizados os resultados alcançados durante as sessões e para o presente estudo estão representados nas sessões 1, 6 e 10. A pessoa envolvida foi designada por "Pessoa", salvaguardando a confidencialidade dos dados e o anonimato da mesma. Desta forma a confidencialidade individual e da clínica hospitalar foram preservados. 0 respeito pelos princípios da Beneficência; Não Maleficência; Fidelidade; Justiça; Veracidade e Confidencialidade das diretrizes éticas para a investigação em enfermagem emanados pelo colégio internacional de enfermagem foram seguidos e a pessoa foi informada dos direitos na participação no estudo ${ }^{(17)}$. Foi obtido o consentimento livre e esclarecido antes da colheita de dados.

De forma a avaliar, quantificar e evidenciar a força muscular, o equilíbrio e a funcionalidade recorreu-se a instrumentos de medida presentes no documento emanado pela Ordem de Enfermagem "Instrumentos de recolha de dados para a documentação dos cuidados de enfermagem de reabilitação" (18). Nomeadamente à Escala Medical Research Council modificada (MRC modificada) por ser mais sensível à mudança e mais responsiva. Para avaliar o equilíbrio preferiu-se a Escala de Tinetti ${ }^{(19)}$ por ser de mais fácil aplicabilidade já que não requer equipamentos sofisticados e para avaliar a funcionalidade recorreu-se ao Índice de Barthel e a Medida de Independência Funcional (MIF) ${ }^{(20)}$ na avaliação das AVD e a avaliação da dor através da escala numérica.

\section{Apresentação do caso}

\section{Anamnese}

Como fio condutor, a anamnese orienta o profissional de saúde para o diagnóstico e respetivo plano terapêutico, através da identificação dos antecedentes pessoais, da história familiar e socioeconómica, bem como da história clínica atual.

0 presente caso corresponde a uma pessoa de 62 anos de idade, género feminino, caucasiana, de nacionalidade portuguesa. É casada e sem filhos. Não foi possível apurar o nível de escolaridade ou situação laboral. A pessoa foi encontrada caída na via pública com alteração da articulação verbal e diminuição da força muscular do hemicorpo direito, sendo encaminhada para o Serviço de Urgência. À chegada a pessoa encontrava-se vígil, afásica, não cumpria ordens com plegia do hemicorpo direito. $\mathrm{Na}$ sequência deste episódio realizou Tomografia Computorizada cranioencefálica (TC CE) e angio TC-CE que evidenciou oclusão da Artéria Carótida Interna $(\mathrm{ACl})$ esquerda. Por hora da instalação dos défices ser superior a 4horas e 
meia, não realizou recanalização farmacológica através de trombólise endovenosa com Recombinant Tissue Plasminogen Activator (EV-rtPA), mas apenas trombectomia endovascular (TEV) que resultou na recanalização parcial da artéria, de acordo com o protoloco institucional.

Após estabilidade hemodinâmica foi transferida para o hospital da área de referência com o diagnóstico de AVC isquémico com oclusão do território da $\mathrm{ACl}$ esquerda. $\mathrm{E}$ devido a infeção do trato respiratório iniciou antibioterapia.

Admitida no serviço de neurologia, vígil, confusa e ansiosa. À chegada apresentava afasia global, emitia sons incompreensíveis e cumpria ordens simples de forma inconsistente. Exibia parésia facial central direita com apagamento do sulco nasogeniano direito e por disfagia foi entubada nasogastricamente. Hemiparésia direita de predomínio braquial distal (Força grau 4 no membro superior direito), plegia da mão direita e força grau 4 no membro inferior direito e ainda hemihipostesia álgica no hemicorpo afetado. No hemicorpo esquerdo a força encontrava-se mantida (grau 5) bem como a sensibilidade.

Como antecedentes pessoais conhecidos apresenta dislipidemia, fibrilhação auricular, AVC em 2012 sem sequelas, alcoolismo e tabagismo, sem cumprimento de medicação. Desconhece alergias.

Independente nas AVD antes do internamento, atualmente, sem suporte familiar que the permita a satisfação das necessidades das suas AVD, no regresso a casa. Já que o processo de alta deve habilitar a pessoa a maximizar o seu potencial para o bem-estar, foi referenciada para a equipa de gestão de altas, no sentido de obter uma resposta social que colmate as necessidades funcionais que a pessoa neste momento apresenta $^{(6)}$.

\section{Avaliação de Enfermagem de Reabilitação}

Para a implementação de um programa de reabilitação é necessário incluir os dados obtidos através da anamnese, da avaliação do exame neurológico, da observação de exames complementares de diagnóstico e da implementação de instrumentos de medida.

Realizada a avaliação inicial por forma a se obter uma visão global da pessoa em estudo. O plano de reabilitação teve início no quarto dia de internamento, tendo as respetivas intervenções sido implementadas durante mês e meio. Posteriormente a pessoa teve alta clínica para uma unidade de reabilitação.

Com base numa avaliação holística foi realizada a avaliação do estado mental, pares cranianos, avaliação da sensibilidade, da força muscular e do equilíbrio que permitiu identificar os diagnósticos de enfermagem e determinar os ganhos sensíveis aos cuidados de enfermagem de reabilitação.
Avaliação do Estado Mental:

No momento da admissão no serviço de neurologia, a pessoa encontrava-se vígil com aparente orientação na pessoa e desorientação no espaço e no tempo.

Aquando da implementação do programa de reabilitação, a pessoa apresentava distúrbio cognitivo, inatenção, sem perceção da sua situação atual, pouco recetiva aos cuidados.

No final do programa, momento da alta, a pessoa aparentava orientação espacial, mas sem possibilidade de se compreender a sua orientação concreta no espaço e no tempo. Apresentava participação inconsistente nos cuidados. Eutímia. Mantendo a afasia, com emissão de sons incompreensíveis pelo que não foi possível avaliar a memória. No entanto, cumpria ordens simples e complexas.

\section{Avaliação de pares cranianos:}

Não foi possível obter a resposta da avaliação de todos os pares cranianos. Por alterações na comunicação, não se conseguiu obter informação acerca de alterações olfativas. Ao nível dos campos visuais e movimentos oculares, a pessoa aparentemente não apresenta defeitos assim como sem evidência de limitações dos movimentos oculares de perseguição. Ao nível auditivo, apesar de não apresentar resposta verbal, reage quando chamada pelo nome, dirigindo o olhar. É visível a parésia facial central direita com apagamento do sulco nasogeniano direito.

$\mathrm{Na}$ admissão ao serviço de internamento, a pessoa encontrava-se entubada nasogastricamente por presença de disfagia na fase oral e faríngea com engasgos para líquidos finos, que não resolve, e texturas mistas. Neste contexto e englobado no plano de reabilitação em conjunto com diversos profissionais de saúde, iniciou exercícios e técnicas de reabilitação com a terapeuta da fala. Com uma evolução favorável, após três semanas iniciou hidratação oral com espessante e, foi extubada nasogastricamente. No final do internamento alimentava-se de dieta via oral sem disfagia para líquidos ou para sólidos.

\section{Avaliação da Sensibilidade:}

De difícil avaliação pelas alterações da perceção e da comunicação que apresenta foi possível obter uma resposta da avaliação térmica e dolorosa. No entanto não foi possível avaliar a sensibilidade superficial e profunda.

\section{Avaliação da Força Muscular:}

Através da escala de MRC modificada verificou-se a evolução dos ganhos da força ao nível do hemicorpo direito (Força grau 4+/5) à exceção da mão direita que mantém a plegia (força $0 / 5$ ).

\section{Avaliação do Equilíbrio:}

0 índice de Tinetti classifica o equilíbrio sentado e em pé, a marcha, assim como mudanças de direção. 
Composto por duas partes, avalia o equilíbrio estático e o equilíbrio dinâmico na posição sentada, em pé e na marcha. Aplicado a primeira parte do teste, avaliou-se o equilíbrio estático e dinâmico nos nove subtópicos (sentado na cadeira, no levantar-se, em pé o equilíbrio imediato, pequenos desequilíbrios na mesma posição, de olhos fechados na mesma posição, girar sobre si mesmo, apoio unipodal e sentar-se). Apresentou um score inicial de 3/16 aquando da implementação do programa de reabilitação, com alterações evidentes no equilíbrio estático e dinâmico. E ao longo do programa obteve-se com evolução positiva no ganho de equilíbrio e no momento da alta apresentava equilíbrio estático e dinâmico sentada e de pé com um score final de 14/16.

\section{Avaliação do tónus muscular:}

Aplicada a escala de Ashworth que evidencia a manutenção do tónus muscular do hemicorpo à direita sem evidência de espasticidade.

\section{Coordenacão Motora:}

Na avaliação do membro superior:

Prova dedo-nariz - Obedece corretamente à ordem e realiza a prova com o braço esquerdo. Com o braço direito faz o movimento, mas não consegue complementar o mesmo por plegia da mão.

Prova da Barany - Obedece à prova com o dedo indicador esquerdo, toca no dedo indicador do enfermeiro. Não consegue realizar a prova com o indicador direito $(0 / 5)$.

\section{Na avaliação do membro inferior:}

Prova calcanhar-joelho - Realiza corretamente sem dificuldade a prova com a perna esquerda (força 5/5). Com a perna direita, apresenta ligeira dismetria, mas realiza o movimento (força $4+/ 5$ ).

\section{Diagnósticos de enfermagem}

No âmbito do programa de reabilitação de equilíbrio corporal foram identificados os seguintes diagnósticos de enfermagem relacionados com os focos "movimento muscular", "equilíbrio corporal”, “transferir" e "andar":

- Movimento muscular diminuído no corpo direito;

- Potencial para melhorar conhecimento sobre técnicas de exercício muscular e articular [no corpo direito];

- Potencial para melhorar capacidade para executar técnicas de exercício muscular e articular [no corpo direito];

- Equilíbrio corporal comprometido;

- Potencial para melhorar conhecimento sobre técnica de equilíbrio corporal;

- Potencial para melhorar capacidade para usar técnica de equilíbrio corporal;

- Potencial para melhorar conhecimento sobre técnica de adaptação para transferir-se;

- Potencial para melhorar a capacidade para usar técnica adaptativa para transferir-se;

- Potencial para melhorar conhecimento sobre andar;

- Potencial para melhorar capacidade para andar.

\section{Programa de reabilitação da função motora - Equilíbrio corporal}

Para cada diagnóstico de enfermagem identificado foram desenvolvidas intervenções de EEER, após avaliação do equilíbrio corporal, com base no Padrão Documental dos Cuidados de Enfermagem da Especialidade de Enfermagem de Reabilitação ${ }^{(15)}$ e de acordo com a linguagem CIPE (tabela 1).

\section{Diagnóstico de Enfermagem}

\section{Intervenções de Enfermagem}

- Executar técnica de exercício muscular e articular passivo [em padrão inibitório de espasticidade, no sentido distal-proximal, respeitando, limiar da dor e amplitude articular, assim como planos e eixos - flexão/extensão, adução/abdução dos dedos da mão com oponência do polegar; Flexão/hiperextensão do punho, com desvio radial/cubital; Supinação/pronação do antebraço; Flexão/extensão do cotovelo; flexão/extensão, adução/abdução, rotação interna/externa, circundação, elevação/depressão do ombro.

Movimento muscular Flexão/extensão dos dedos do pé; Inversão/eversão tibiotársica; Dorsiflexão/flexão plantar; Flexão/extensão do joelho; Rotação interna e externa, adução/abdução, flexão/extensão, circundação da coxofemoral; rotação interna e externa com flexão do joelho e coxofemoral; 1 série de 10 repetições];

corpo direito

- Atividades terapêuticas [Rolamentos para o lado afetado e para o lado são; exercícios de ponte com e sem bola; flexão/ extensão controlada da anca; automobilização do membro superior e inferior; carga sensitiva no cotovelo; (facilitação cruzada) - 1 série de 10 repetições]. 
- Avaliar conhecimento sobre técnicas de exercício muscular e articular;

Potencial para melhorar conhecimento sobre técnicas de exercício muscular e articular [no corpo direito]
- Ensinar sobre técnicas de exercício muscular e articular [Exercícios ativos: técnica de automobilização do hemicorpo direito (membro superior: entrelaçar as mãos com as palmas em contacto; estender o cotovelo, elevar as mãos acima da cabeça, obtendo a protração do ombro; membro inferior: colocar a perna afetada por cima da perna não afetada e promover a flexão e extensão) - 1 série de 10 repetições];

- Ensinar sobre técnicas de atividades terapêuticas [Rolamentos para o lado afetado e para o lado são; exercícios de ponte e ponte com bola; flexão/ extensão controlada da anca; automobilização do membro superior e inferior; carga sensitiva no cotovelo; facilitação cruzada) - 1 série de 10 repetições].

- Avaliar capacidade para executar técnicas de exercício muscular e articular [no hemicorpo direito];

- Instruir sobre técnicas de exercício muscular e articular [Exercícios ativos: técnica de automobilização do hemicorpo direito (membro superior: entrelaçar as mãos com as palmas em contacto; estender o cotovelo, elevar as mãos acima da cabeça, obtendo a protração do ombro; membro inferior: colocar a perna afetada por cima da perna não afetada e promover a flexão e extensão) - 1 série de 10 repetições]; melhorar capacidade para executar técnicas de exercício muscular e articular [no corpo direito]

- Instruir sobre técnicas de atividades terapêuticas [(Rolamentos para o lado afetado e para o lado são; exercícios de ponte e ponte com bola; flexão/ extensão controlada da anca; automobilização do membro superior e inferior; carga sensitiva no cotovelo; facilitação cruzada) - 1 série de 10 repetições];

- Treinar técnicas de exercício muscular e articular [no hemicorpo direito - Exercícios ativo: técnica de automobilização do hemicorpo direito (membro superior: entrelaçar as mãos com as palmas em contacto; estender o cotovelo, elevar as mãos acima da cabeça, obtendo a protração do ombro; membro inferior: colocar a perna afetada por cima da perna não afetada e promover a flexão e extensão - 1 série de 10 repetições];

- Treinar técnicas de atividades terapêuticas [(Rolamentos para o lado afetado e para o lado são; exercícios de Ponte e ponte com bola; flexão/ extensão controlada da anca; automobilização do membro superior e inferior; carga sensitiva no cotovelo; facilitação cruzada) - 1 série de 10 repetições].

- Monitorizar equilíbrio corporal através de escala [Índice de Tinetti];

- Avaliar equilíbrio corporal [equilíbrio estático e dinâmico sentada e ortostático];

- Estimular a manter equilíbrio corporal [correção postural];

- Executar técnica de treino de equilíbrio correção postural, facilitação cruzada, exercício de

Equilíbrio corporal comprometido no chão; sentada na cama com os braços esticados para a frente e para a esquerda/ direita) e dinâmico sentado (induzir ligeiro balanço nos ombros da pessoa de forma a que esta compense o movimento; induzir ligeiro balanço com bola suíça nas costas);

equilíbrio estático de pé (de pé com braços ao longo do tronco, de pé com braços estendidos, de pé com os olhos fechados) e dinâmico de pé (exercícios realizados ao fundo da cama/ barra lateral do corredor com o enfermeiro: alternância de carga nos membros inferiores, flexão do joelho, flexão/extensão coxofemoral, elevação lateral da perna (em abdução), agachamentos com correção postural, levantar/sentar sem apoio de mãos)].

- Avaliar conhecimento sobre técnica de equilíbrio corporal;

- Ensinar sobre técnica de equilíbrio corporal correção postural, facilitação cruzada, exercício de equilíbrio estático sentado (sentada na cama com as mãos apoiadas na cama e os pés apoiados no chão; sentada na cama com os braços esticados para a frente e para a esquerda/ direita) e dinâmico sentado (induzir ligeiro balanço nos ombros da pessoa de forma a que esta compense o movimento; induzir ligeiro balanço com bola suíça nas costas);

equilíbrio estático de pé (de pé com braços ao longo do tronco, de pé com braços estendidos, de pé com os olhos fechados) e dinâmico de pé (exercícios realizados ao fundo da cama/ barra lateral do corredor com o enfermeiro: alternância de carga nos membros inferiores, flexão do joelho, flexão/extensão coxofemoral, elevação lateral da perna (em abdução), agachamentos com correção postural, levantar/sentar sem apoio de mãos)]. 
- Avaliar capacidade para executar técnica de equilíbrio corporal;

- Instruir sobre técnica de equilíbrio corporal [correção postural, facilitação cruzada, exercício de equilíbrio estático sentado (sentada na cama com as mãos apoiadas na cama e os pés

Potencial para melhorar apoiados no chão; sentada na cama com os braços esticados para a frente e para a esquerda/ capacidade para usar técnica de equilíbrio corporal direita) e dinâmico sentado (induzir ligeiro balanço nos ombros da pessoa de forma a que esta compense o movimento; induzir ligeiro balanço com bola suíça nas costas);

equilíbrio estático de pé (de pé com braços ao longo do tronco, de pé com braços estendidos, de pé com os olhos fechados) e dinâmico de pé (exercícios realizados ao fundo da cama/ barra lateral do corredor com o enfermeiro: alternância de carga nos membros inferiores, flexão do joelho, flexão/extensão coxofemoral, elevação lateral da perna (em abdução), agachamentos com correção postural, levantar/sentar sem apoio de mãos)].

-Treinar técnica de equilíbrio corporal.

Potencial para melhorar conhecimento sobre técnica de adaptação para transferirse
- Avaliar conhecimento sobre técnica de adaptação para transferir-se;

- Ensinar sobre técnica de adaptação para transferir-se [técnica de levante: no leito - Rodar o tronco para o lado afetado, colocar as pernas fora do leito, apoiando o cotovelo afetado na cama. Elevar o tronco até à posição sentada com os pés apoiados no chão; técnica de transferência: colocar o cadeirão junto à cama (ângulo $30^{\circ}$ ), com as rodas travadas. Apoiar o braço são no cadeirão, rodar (travar os joelhos da pessoa) e sentar no cadeirão. A transferência para a cama segue os mesmos passos em sentido inverso].

- Avaliar capacidade de aprendizagem para usar técnica de adaptação para transferir-se;

Potencial para melhorar a capacidade para usar técnica adaptativa para transferir-se

- Instruir sobre técnica de adaptação para transferir-se levantar e sair da cama [técnica de levante: no leito - Rodar o tronco para o lado afetado, colocar as pernas fora do leito, apoiando o cotovelo afetado na cama. Elevar o tronco até à posição sentada com os pés apoiados no chão; técnica de transferência: colocar o cadeirão junto à cama (ângulo $30^{\circ}$ ), com as rodas travadas. Apoiar o braço são no cadeirão, rodar (travar os joelhos da pessoa) e sentar no cadeirão. A transferência para a cama segue os mesmos passos em sentido inverso].

- Avaliar conhecimento sobre técnica de adaptação para andar;

Potencial para melhorar - Ensinar sobre técnica de adaptação para andar;

conhecimento sobre andar

- Ensinar sobre andar: subir e descer escadas [Subir: apoiar a mão sã no corrimão; $1^{\circ}$ membro inferior são; $2^{\circ}$ membro inferior parético; Descer: Apoiar a mão sã no corrimão; $1^{\circ}$ membro inferior parético; $2^{\circ}$ membro inferior são];

- Avaliar capacidade para andar [Anda com passadas eficazes a diferentes ritmos];

Potencial para melhorar capacidade para andar
- Instruir sobre técnica de adaptação para andar;

- Instruir sobre andar: subir e descer escadas [Subir: apoiar a mão sã no corrimão; $1^{\circ}$ membro inferior são; $2^{\circ}$ membro inferior parético; Descer: Apoiar a mão sã no corrimão; $1^{\circ}$ membro inferior parético; $2^{\circ}$ membro inferior são];

- Treinar a técnica de adaptação para subir e descer escadas.

Tabela 1: Diagnósticos e Intervenções de Enfermagem

As intervenções acima mencionadas (tabela 1) foram asseguradas nas diversas sessões realizadas e contabilizaram cerca de 30 a 45 minutos. Os exercícios implementados foram adaptados do programa de EEER do serviço de neurologia e ajustados à pessoa com base no padrão documental acima referido.

\section{RESULTADOS}

O programa de reabilitação da função motora Equilíbrio corporal contemplou um total de dez sessões, em dias alternados nos meses de março, abril e maio.

Alterações neurológicas nomeadamente orientação podem comprometer a resposta da pessoa na participação das sessões. Apesar de vígil, numa fase inicial da implementação do programa, a pessoa apresentava défice de atenção que a impedia de realizar todos os exercícios de forma consistente. Contudo foi possível realizar as dez sessões propostas.

A manutenção do equilíbrio na posição ortostática é uma tarefa complexa que exige a manutenção de uma postura corporal com um mínimo de oscilação. A avaliação do equilíbrio foi realizada pelo índice de Tinetti (tabela 2$)^{(19)}$. Este teste permite realizar a avaliação da mobilidade (marcha) e equilíbrio estático e dinâmico. Segue em baixo a tabela com os itens e os três momentos distintos do programa de reabilitação que foram alvo de avaliação. 
Índice de Tinetti - Equilíbrio Estático e Dinâmico

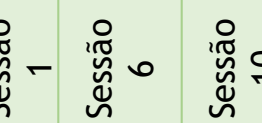

Inclina-se ou desliza na cadeira $=0$

1 - Equilíbrio sentado

Inclina-se ligeiramente ou aumenta a distância das nádegas ao encosto da cadeira $=1$

Estável, seguro $=2$

Incapaz sem ajuda ou perde o equilíbrio $=0$

Capaz, mas usa os braços para ajuda ou faz excessiva flexão do trono ou não consegue à $1^{\mathrm{a}}$ tentativa $=1$

Capaz na $1^{\text {a }}$ tentativa sem usar os braços $=2$

Instável (cambaleia, move os pés, oscila o tronco, tentar agarrar

3 - Equilíbrio imediato (primeiros 5 segundos)

algo para suportar-se) $=0$

Estável, mas usa dispositivo auxiliar de marcha para suportar-se $=1$

Estável sem qualquer tipo de ajudas $=2$

Instável $=0$

4 - Equilíbrio em pé com os pés paralelos

Instável, mas alargando a base de sustentação (calcanhares afastados $>10 \mathrm{~cm}$ ) ou recorre a auxiliar de marcha $=1$

Pés próximos e sem ajudas $=2$

5 - Pequenos desequilíbrios na mesma posição (na posição de pé com os pés próximos, o observador empurra-o levemente com a palma da mão, 3 vezes ao nível do esterno)

6 - Fechar os olhos na mesma posição

Começa a cair $=0$

Cambaleia, segura-se, consegue manter o equilíbrio $=1$

Estável $=2$

Instável $=0$

Estável $=1$

Instável (segura-se, cambaleia) $=0$

7 - Volta de $360^{\circ}$ (2 vezes)

Estável, mas dá passos descontinuados $=1$

Estável e passos contínuos $=2$

8 - Apoio unipodal (aguenta pelo menos 5 segundos de forma estável)

9 - Sentar-se

Não consegue ou tenta segurar-se a qualquer objeto $=0$

Aguenta 5 segundos de forma estável $=1$

Pouco seguro ou cai na cadeira ou calcula mal a distância) $=0$

Usa os braços ou movimento não harmonioso $=1$

Seguro, movimento harmonioso $=2$

Total

$3 / 16 \quad 9 / 16$

Tabela 2 - Índice de Tinetti ${ }^{19}$

Após estabilidade hemodinâmica e de acordo com o programa de reabilitação implementado, na sessão 1 foi possível realizar o $1^{\circ}$ levante, com presença de equilíbrio estático sentado, mas com défice de equilíbrio dinâmico sentado e presença de instabilidade no equilíbrio em pé $(3 / 16)$. Na sexta sessão pelo score atingido (9/16) verifica-se uma evolução no equilíbrio dinâmico sentado e no equilíbrio estático em pé. Já o equilíbrio dinâmico em pé mantém-se com alterações, nomeadamente pequenos desequilíbrios, necessitando de se apoiar, apresenta um aumento da base de apoio, cambaleando. Na última avaliação realizada, atingindo quase a pontuação máxima (14/16), apesar de aumentar ligeiramente a base de apoio para manter 0 equilíbrio, esta é menor que em avaliações anteriores. Consegue sentar-se com movimentos suaves e sem recorrer a dispositivos auxiliares de marcha e consegue ainda deambular pelo corredor sem desequilíbrio. No entanto o apoio unipodal (durante 5 segundos), não foi possível verificar sem a tentativa de se segurar em algum objeto para manter o equilíbrio.

Nas primeiras sessões é evidente a necessidade de apoio de 2 pessoas para a manutenção do equilíbrio corporal. A partir da sessão 4 , a pessoa realiza as técnicas de equilíbrio sentado na presença de enfermeiro. $\mathrm{Na}$ sessão 6 realiza as técnicas de equilíbrio dinâmico ortostático na presença do EEER. E na última sessão, realiza os exercícios quando solicitada, no entanto, devido a alterações cognitivas (défice de atenção), nem sempre cumpre o solicitado na íntegra. Perante esta situação não foi aplicada a segunda parte do teste de Tinetti de equilíbrio dinâmico referente à marcha, por não ser conseguir avaliar de forma fidedigna todos os itens contemplados, no entanto, a dimensão de 
conhecimento e aprendizagem do foco equilíbrio foi demonstrada pela pessoa (tabela 3 ).

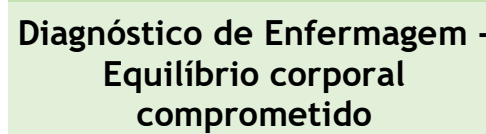

$\begin{array}{ccc}\text { Sessão } & \text { Sessão } & \text { Sessão } \\ 1 & 6 & 10\end{array}$

Potencial para melhorar conhecimento sobre técnica de equilíbrio corporal

\begin{tabular}{l|l|l} 
ND & $D$ & $D$
\end{tabular}

Potencial para melhorar capacidade para usar técnica ND D D de equilíbrio corporal

Legenda: D - Demonstra; ND - Não Demonstra

Tabela 3 - Avaliação da dimensão conhecimento e aprendizagem do foco equilíbrio corporal

A força muscular foi avaliada e contemplada no programa de reabilitação (tabela 4), verifica-se uma melhoria nos segmentos corporais avaliados no hemicorpo direito. Foram implementados diversos exercícios de força, equilíbrio e coordenação motora ao longo das 10 sessões. Das avaliações realizadas verificam-se ganhos ao nível da força muscular nos membros superior e inferior direitos. A mobilidade dos tecidos moles envolve, entre outros, a amplitude de movimento e a coordenação neuromuscular para executar o movimento de forma adequada. Com a melhoria dos mesmos pode-se então realizar a preparação para a posição ortostática e consequente melhorar a estabilidade de tronco ${ }^{(10)}$.

Pelos dados apresentados, não houve qualquer evolução ao nível do punho e dedos, mantendo-se a plégia dos segmentos. No entanto, os ganhos apresentados na sessão 10 e cruzando com os dados obtidos no índice de Tinetti, permite afirmar que o equilíbrio corporal e a força muscular foram melhoradas e fortalecidas ao longo das sessões.

Exercícios de fortalecimento muscular e treino de AVD como já referido melhoram a funcionalidade, a força muscular e a velocidade do andar ${ }^{(5)}$. Através da aplicação do índice de Barthel consegue-se compreender a evolução ao longo do internamento e verifica-se que a alteração no equilíbrio está estreitamente associada às alterações aqui apresentadas ao nível de dependência (tabela 5) ${ }^{(20)}$.

$\mathrm{Na}$ sessão 1 , a avaliação no $1^{\circ}$ levante apresenta dependência severa (score 15) apenas na alimentação, transferência e vestir-se apresenta uma dependência moderada. No entanto, verificou-se que associado ao ganho de equilíbrio e à melhoria observada ao nível cognitivo (apresentar-se mais orientada espacialmente), existiu um ganho de funcionalidade traduzida em 30 pontos (score 45 ). Na sessão 10, a pessoa teve uma avaliação com score de 60/100 a que se deve em parte à independência alcançada na mobilidade, transferência e subir/descer escadas. Por não apresentar controlo de esfíncteres e necessitar ajuda parcial nos cuidados de higiene, fundamenta a dependência moderada obtida no final do internamento.

\begin{tabular}{|c|c|c|c|c|}
\hline \multirow{2}{*}{\multicolumn{2}{|c|}{$\begin{array}{c}\text { Segmentos } \\
\text { (Hemicorpo direito) }\end{array}$}} & \multicolumn{3}{|c|}{ Sessão Sessão Sessão } \\
\hline & & 1 & 6 & 10 \\
\hline \multicolumn{5}{|c|}{ Membro Superior } \\
\hline \multirow{6}{*}{$\begin{array}{l}\text { Escapulo- } \\
\text { umeral }\end{array}$} & Flexão & $4 / 5$ & $4 / 5$ & $4+/ 5$ \\
\hline & Extensão & $4 / 5$ & $4 / 5$ & $4+/ 5$ \\
\hline & Adução & $4 / 5$ & $4 / 5$ & $4+/ 5$ \\
\hline & Abdução & $4 / 5$ & $4 / 5$ & $4+/ 5$ \\
\hline & Rotação externa & $4 / 5$ & $4 / 5$ & $4+/ 5$ \\
\hline & Rotação interna & $4 / 5$ & $4 / 5$ & $4+/ 5$ \\
\hline \multirow{2}{*}{ Cotovelo } & Flexão & $4 / 5$ & $4 / 5$ & $4+/ 5$ \\
\hline & Extensão & $4-/ 5$ & $4 / 5$ & $4+/ 5$ \\
\hline \multirow{2}{*}{ Antebraço } & Pronação & $4-/ 5$ & $4 / 5$ & $4+/ 5$ \\
\hline & Supinação & $4-/ 5$ & $4 / 5$ & $4+/ 5$ \\
\hline \multirow{2}{*}{ Punho } & Flexão & $0 / 5$ & $0 / 5$ & $0 / 5$ \\
\hline & Extensão & $0 / 5$ & $0 / 5$ & $0 / 5$ \\
\hline \multirow{2}{*}{ Dedos } & Flexão/extensão & $0 / 5$ & $0 / 5$ & $0 / 5$ \\
\hline & Adução/abdução & $0 / 5$ & $0 / 5$ & $0 / 5$ \\
\hline \multicolumn{5}{|c|}{ Membro Inferior } \\
\hline \multirow{4}{*}{$\begin{array}{l}\text { Coxo- } \\
\text { Femoral }\end{array}$} & Flexão & $4-/ 5$ & $4 / 5$ & $4+/ 5$ \\
\hline & Extensão & $4-/ 5$ & $4 / 5$ & $4+/ 5$ \\
\hline & Adução & $4-/ 5$ & $4 / 5$ & $4+/ 5$ \\
\hline & Abdução & $4-/ 5$ & $4 / 5$ & $4+/ 5$ \\
\hline \multirow{2}{*}{$\begin{array}{l}\text { Tibio- } \\
\text { társica }\end{array}$} & Flexão plantar & $4-/ 5$ & $4 / 5$ & $4+/ 5$ \\
\hline & Flexão dorsal & $4-/ 5$ & $4 / 5$ & $4+/ 5$ \\
\hline
\end{tabular}

Legenda:

\begin{tabular}{|c|l|}
\hline Grau & \multicolumn{1}{|c|}{ Definição } \\
\hline $\mathbf{5}$ & Força Normal contra resistência e contra gravidade \\
\hline $\mathbf{5 -}$ & Fraqueza dificilmente detetável \\
\hline $\mathbf{4 +}$ & $\begin{array}{l}\text { A mesma que o grau 4, mas o músculo suporta a articulação } \\
\text { contra resistência de moderada a máxima }\end{array}$ \\
\hline $\mathbf{4}$ & $\begin{array}{l}\text { O músculo suporta a articulação contra uma combinação de } \\
\text { gravidade e resistência moderada }\end{array}$ \\
\hline $\mathbf{4 -}$ & $\begin{array}{l}\text { A mesma que o grau 4, mas o músculo suporta a articulação } \\
\text { apenas contra uma resistência mínima. }\end{array}$ \\
\hline $3+$ & $\begin{array}{l}\text { O músculo move a articulação totalmente contra a gravidade e } \\
\text { é capaz da resistência transitória, contudo cai abruptamente }\end{array}$ \\
\hline 3 & $\begin{array}{l}\text { O músculo não consegue suportar a articulação, mas move a } \\
\text { mesma totalmente contra a gravidade }\end{array}$ \\
\hline $3-$ & $\begin{array}{l}\text { O músculo move a articulação contra a gravidade, mas não } \\
\text { realiza todos os movimentos mecânicos }\end{array}$ \\
\hline $\mathbf{2}$ & O músculo move a articulação, mas não contra gravidade \\
\hline $\mathbf{1}$ & Observa-se contração muscular, mas não há movimento \\
\hline $\mathbf{0}$ & Sem contração muscular e sem movimento \\
\hline
\end{tabular}

Tabela 4 - Avaliação do movimento muscular no hemicorpo direito através da Escala de MRC Modificada

\begin{tabular}{|c|c|c|c|}
\hline ÍNDICE DE BARTHEL & Sessão 1 & Sessão 6 & Sessão 10 \\
\hline Total & 15 & 45 & 60 \\
\hline
\end{tabular}

Legenda:

\begin{tabular}{|l|l|l|l|}
\hline Score & Classificação & Score & Classificação \\
\hline $61-100$ & Dependência leve & $21-40$ & Dependência severa \\
$41-60$ & Dependência moderada & $0-20$ & Dependência total \\
\hline
\end{tabular}

Tabela 5 - Índice de Barthel 
$\mathrm{Na}$ avaliação da medida de independência funcional $(M I F)^{(20)}$ na sessão 1 , verifica-se um score de 31 , justificada pelos défices em quase todas as AVD e pelas alterações ao nível cognitivo. No decorrer do internamento verifica-se ganhos ao nível das AVD e na sessão 10 a pessoa alcançou um score 72/100. Os défices funcionais devem-se à incontinência de esfíncteres e às alterações cognitivas que apesar de apresentar melhoria mantém algumas alterações, nomeadamente: compreensão, afasia, défice de atenção.

\begin{tabular}{|c|c|c|c|c|}
\hline \multirow{2}{*}{\multicolumn{2}{|c|}{$\begin{array}{l}\text { MEDIDA DE } \\
\text { INDEPENDÊNCIA } \\
\text { FUNCIONAL }\end{array}$}} & Sessão 1 & Sessão 6 & Sessão 10 \\
\hline & & $28 / 03$ & $22 / 04$ & $13 / 05$ \\
\hline \multicolumn{2}{|r|}{$\begin{array}{l}\text { Score sub-total } \\
\text { motor }\end{array}$} & 16 & 39 & 48 \\
\hline \multicolumn{2}{|r|}{$\begin{array}{l}\text { Score Subtotal } \\
\text { Cognitivo }\end{array}$} & 15 & 19 & 24 \\
\hline \multicolumn{2}{|r|}{ Score Total } & 31 & 48 & 72 \\
\hline \multicolumn{5}{|c|}{$\begin{array}{l}\text { Legenda: } \\
\text { Independência Total - } 126 \\
\text { Dependência Total - } 18\end{array}$} \\
\hline \multicolumn{5}{|c|}{ 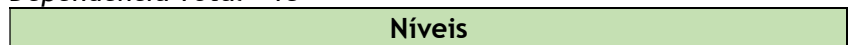 } \\
\hline \multicolumn{5}{|c|}{ Sem Ajuda } \\
\hline 7 & \multicolumn{4}{|c|}{ Independência completa (em segurança, em tempo normal) } \\
\hline 6 & \multicolumn{4}{|c|}{ Independência modificada (ajuda técnica) } \\
\hline \multicolumn{5}{|c|}{ Com Ajuda } \\
\hline \multicolumn{5}{|c|}{ Dependência Modificada } \\
\hline 5 & \multicolumn{4}{|c|}{ Supervisão } \\
\hline 4 & \multicolumn{4}{|c|}{ Ajuda mínima $(\geq 75 \%)$} \\
\hline 3 & \multicolumn{4}{|c|}{ Ajuda moderada $(\geq 50 \%)$} \\
\hline \multicolumn{5}{|c|}{ Dependência Completa } \\
\hline 2 & \multicolumn{4}{|c|}{ Ajuda máxima ( $\geq 25 \%)$} \\
\hline 1 & \multicolumn{4}{|c|}{ Ajuda total $(\geq 0 \%)$} \\
\hline
\end{tabular}

Tabela 6 - Medida de Independência Funcional (MIF)

\section{DISCUSSÃO}

Perante os resultados obtidos, o presente estudo de caso identifica a efetividade da intervenção do EEER na prescrição e implementação de exercícios que promovem a recuperação do equilíbrio postural na pessoa com AVC isquémico.

Referido por diversos autores, a perda de equilíbrio corporal é uma consequência provável nas pessoas após AVC que condiciona a recuperação da marcha e da aquisição da independência funcional nas AVD. Por outro lado, aqueles que se mostram capazes de retomar a posição em pé, esta é tipicamente caracterizada pelo aumento da oscilação durante a postura estática e pela distribuição assimétrica do peso dos membros inferiores, conduzindo a distúrbios na marcha, equilíbrio e AVD ${ }^{(8,13)}$.

Indo de encontro ao descrito, os resultados obtidos no índice de Tinetti comprovam que as alterações de equilíbrio em pessoas com AVC são evidentes (na $1^{\text {a }}$ avaliação obteve-se um score $3 / 16$ ) pelo que a implementação de um programa de reabilitação deve ser realizada o mais precocemente possível.
Ao longo do internamento com o plano de reabilitação instituído verificaram-se ganhos ao nível da força muscular, do equilíbrio postural, tanto na posição sentada como na posição de pé e posterior marcha, assim como na AVD.

No plano de cuidados realizado, foram implementados diferentes exercícios de acordo com o equilíbrio que a pessoa ia alcançando. Assim, após a $1^{\text {a }}$ avaliação iniciaram-se mobilizações passivas do hemicorpo direito, evoluindo para mobilizações ativas livres (à exceção da mão direita que por se encontrar plégica, mantiveram-se mobilizações passivas). Foram instituídas atividades e exercícios terapêuticos como o rolar e levantar, ponte (com e sem bola) no sentido de preparar para a posição sentada e ortostática(10).

Para Haruyama e colaboradores, exercícios pélvicos aumentam o recrutamento dos músculos globais de estabilidade de tronco pelo que são essenciais para ativar o core no desequilíbrio de tronco em pessoas com AVC. No seu estudo, através de exercícios de ponte modificada permitiu o fortalecimento do core em menor tempo que estudos anteriores, obtendo resultados positivos ao nível do equilíbrio e da mobilidade(12).

Por sua vez Song e colaboradores, referem que exercícios de ponte modificada com os pés sobre uma superfície instável são eficazes para aumentar o equilíbrio dinâmico e a resistência muscular, especialmente na prevenção de danos na coluna vertebral, já que aumenta a estabilização estática e dinâmica da região lombar ${ }^{(9)}$.

No sentido de alcançar o equilíbrio na posição sentada, foi solicitada à pessoa que elevasse os braços para a frente, para cima, para a esquerda e direita na posição sentada, mas nem sempre cumpria todos os movimentos solicitados. Com a bola terapêutica colocada atrás das costas promoveu-se desequilíbrio por forma a que compensasse o mesmo.

Para pessoas após AVC com moderada alteração no equilíbrio de tronco, exercícios de treino lateral da postura corporal sentado numa plataforma inclinada promove o alinhamento corporal e o equilíbrio. Melhora o desempenho de tronco a curto prazo, fortalecendo os seus músculos. Antunes e Fujino realçam que o equilíbrio de tronco está fortemente associado à capacidade de andar e de realizar AVD ${ }^{(8,11)}$.

Pelos resultados obtidos através das escalas de MIF e de Barthel verificam-se que o ganho de equilíbrio é um fator importante para a realização das AVD (banho no chuveiro, transferência, marcha) tal como Fujino e colaboradores referem no seu estudo ${ }^{(11)}$.

Antunes e colaboradores referiram que o controle postural causa grande influência no desempenho da marcha. Para alcançá-la é necessário atingir primeiramente o equilíbrio na posição de pé. Desta feita, no treino de equilíbrio implementado no presente estudo de caso, as atividades basearam-se em exercícios de flexão do joelho, flexão/extensão coxofemoral, elevação lateral da perna (em abdução) e ainda levantar/sentar sem apoio de mãos ${ }^{(8)}$. 
Com exercícios semelhantes aos realizados neste estudo de caso, Lupo e colaboradores verificaram a melhoria das habilidades motoras de equilíbrio de pé através da flexão plantar, flexão do joelho/ coxofemoral, abdução da perna e agachamentos. Contudo, no seu estudo recorreu a um programa de videojogo onde os exercícios realizados eram baseados em atividades do dia-a-dia sobre uma plataforma vibratória e através da resposta de sensores de movimento aplicados nos participantes, concluiu que esta forma de realizar os exercícios estimula as pessoas, motivando-as ${ }^{(13)}$.

Todavia, alcançar o equilíbrio é uma tarefa complexa e quando associado à tecnologia, deve-se ter em consideração a componente cognitiva e as restrições biomecânicas (como amplitudes articulares) ${ }^{(13)}$.

Tal como os exercícios aplicados neste estudo de caso, assim como os diferentes exercícios que foram realizados nos estudos analisados, o objetivo comum foi alcançado. Todos estes exercícios contribuíram para o ganho de equilíbrio corporal e consequente melhoraria da marcha e das AVD, maximizando a independência funcional da pessoa com AVC.

O EEER para além de cuidar de pessoas com necessidades especiais, ao longo do ciclo de vida tem ainda como competências específicas capacitar e maximizar as competências funcionais da pessoa. E permitir um melhor desempenho motor, cardíaco e respiratório, potenciando o rendimento e o desenvolvimento pessoal ${ }^{(13)}$.

O ser humano depara-se com constantes mudanças ao longo do ciclo de vida, quando a pessoa experiencia um evento crítico que provoca alterações no seu conceito de saúde, bem-estar e capacidade de autocuidado cria um processo de transição onde as pessoas tendem a ser mais vulneráveis a riscos que comprometem a sua saúde. De acordo com a Teoria de Meleis, o enfermeiro tem um papel mediador neste processo de transição pois possui conhecimentos estruturados que permitem o diagnóstico e a implementação de intervenções especializadas na orientação da pessoa com vista a maximizar o objetivo terapêutico ${ }^{(21)}$.

Já Dorothea Orem através da Teoria do Défice de Autocuidado de Enfermagem define o autocuidado como "o desempenho ou a prática de atividades que os indivíduos realizam em seu benefício para manter a vida, a saúde e o bem-estar" (21). Não se restringido apenas às AVD ou atividades instrumentais, abrange de forma global os aspetos vivenciais da pessoa.

Este modelo interpreta os défices no autocuidado como limitações parciais ou temporárias que necessitam de ser compensados pelo profissional de enfermagem para manter a maior independência possível da pessoa (22).

Quando a capacidade que a pessoa tem para determinar e gerir as suas necessidades se encontram alteradas é necessário um período de transição de forma a adaptarse à nova realidade. 0 enfermeiro atua como agente terapêutico respondendo às necessidades da pessoa num determinado momento. Com um papel assistencial, o enfermeiro determina como pode ajudar a pessoa, coordena e integra com os diferentes intervenientes os cuidados de enfermagem na vida diária da mesma permitindo assim a assistência de saúde necessária para uma transição ajustada ${ }^{(21-23)}$.

Ambas teorias vêm comprovar a importância da atuação do enfermeiro junto da pessoa nos processos de transição. Fica assim subjacente que o EEER é detentor de conhecimentos específicos e fundamentados para prescrever e implementar exercícios que promovem a recuperação do equilíbrio postural na pessoa com AVC isquémico, com consequente impacto na melhoria da funcionalidade da pessoa.

\section{CONSIDERAÇÕES FINAIS}

Com este estudo de caso foi possível mobilizar e aprofundar conhecimentos acerca do papel que o EEER tem na capacitação da pessoa com AVC. Através da implementação de exercícios que promovem o fortalecimento muscular e implementação de técnicas e exercícios que promovem ganhos ao nível do equilíbrio postural foi possível maximizar a independência da pessoa nas AVD.

Evidenciar que o EEER é um dos elementos dinâmicos da equipa multidisciplinar que promove uma recuperação mais célere e consequentemente uma melhoria na qualidade de vida da pessoa permitiu-nos atingir o objetivo proposto para este estudo de caso.

0 processo de reabilitação contribui para a reintegração tanto física quanto cognitiva da pessoa com AVC. As equipas interdisciplinares deverão trabalhar em conjunto para que o plano de reabilitação desenvolvido envolva ao mesmo tempo as áreas motoras, cognitivas, emocionais, sociais e familiares. 0 programa da reabilitação da pessoa em questão teve a presença de outros profissionais da equipa multidisciplinar, a terapeuta da fala na fase de disfagia e a fisioterapeuta que numa fase de ganho de equilíbrio a pessoa deslocava-se ao ginásio da instituição hospitalar.

A restauração da marcha é um objetivo importante na reabilitação das pessoas com comprometimentos motores relacionados com alterações neurológicas. $\mathrm{E}$ neste sentido surge a maior limitação deste estudo de caso. A pessoa selecionada, apesar de a nível motor apresentar potencial e até se ter conseguido alcançar ganhos ao nível do equilíbrio, por apresentar alterações cognitivas/ comportamentais nem sempre foi possível realizar os exercícios propostos de forma consistente. A afasia dificultou a comunicação, o défice de atenção e desinteresse potenciou a fraca adesão aos exercícios propostos em diferentes dias.

Não foi possível realizar o teste "Timed Up and Go", nem realizar a segunda parte do índice de Tinetti Equilíbrio Dinâmico-Marcha , apesar de serem testes simples, a pessoa não conseguiu executar o exercício completo (atribuído às alterações cognitivas), embora tenha potencial motor para os concluir com êxito, (realiza marcha com boa cadência e sem desequilíbrio) de forma concreta não foi possível comprovar.

Contudo, no decorrer do internamento verifica-se uma evolução no sentido de maior atenção e concentração o 
que possibilitou a introdução de novos exercícios (agachamentos, treino de escadas).

Por fim a outra limitação encontrada deve-se ao facto de existirem poucos estudos de investigação na área de enfermagem de reabilitação que corroborem a importância dos exercícios para o treino de equilíbrio, prescritas por EEER, na recuperação da mobilidade, da força muscular e especificamente do equilíbrio de tronco para a promoção da autonomia e da independência.

A evolução observada é um indicador evidente do trabalho realizado pelo EEER e demonstra a sua efetividade na prescrição de exercícios que melhorem o equilíbrio postural.

Sugere-se em estudos posteriores a realização de sessões mais regulares (diárias, se for possível), de modo a contribuir para um ganho efetivo e precoce do equilíbrio corporal.

\section{REFERÊNCIAS BIBLIOGRÁFICAS}

1. Direcção Geral da Saúde. Programa Nacional de Saúde para as Doenças Cérebro-Cardiovasculares. Lisboa; 2017.

2. Instituto Nacional de Estatística. Causas de Morte 2016. INE, IP: Lisboa; 2018.

3. PORDATA. Óbitos por algumas causas de morte (\%). Instituto Nacional de Estatística. 2019, Abril. Consultado em 8 de Maio 2019. Disponível

em: https://www.pordata.pt/DB/Portugal/Ambiente+de+Consulta/T abela.

4. Ministério da Saúde. Retrato da Saúde 2018. Ministério da Saúde: Lisboa; 2018. Consultado em 8 de Maio 2019. Disponível em: https://www.sns.gov.pt/wpcontent/uploads/2018/04/RETRATODASAUDE2018 compressed.pdf.

5. Marques-Vieira M, Sousa L, Braga R. Reabilitar a Pessoa com Acidente Vascular Cerebral. Marques-Vieira CM, Sousa, LM. (Eds) Cuidados de Enfermagem de Reabilitação à Pessoa ao Longo da Vida. (1 ${ }^{\text {aed. }}$ ) Loures: Lusodidacta; 2017: 465-474.

6. Menoita E, Sousa L, Alvo I, Vieira C. Reabilitar a Pessoa Idosa com AVC: Contributos para um envelhecer resiliente. Loures: Lusociência; 2014.

7. Louie DR, Lim SB, Eng JJ. The Efficacy of Lower Extremity Mirror Therapy for Improving Balance, Gait, and Motor Function Poststroke: A Systematic Review and Meta-Analysis. J Stroke Cerebrovasc Dis. 2019 Jan 1;28(1):107-20.

8. Antunes J, Justo F, Justo A, Ramos G, Prudente C. Influência do controle postural e equilíbrio na marcha de pacientes com sequela de acidente vascular cerebral. Rev Fisioter S Fun. Fortaleza, 2016 Jan-Jul; 5(1): 30-41.

9. Song GB, Heo JY. The effect of modified bridge exercise on balance ability of stroke patients. patient. J Phys Ther Sci. 2015;27(12):3807-10.

10. Coelho C, Barros H, Sousa L. Reeducação da Função Sensoriomotora. Marques-Vieira CM, Sousa, LM. (Eds) Cuidados de Enfermagem de Reabilitação à Pessoa ao Longo da Vida. ( $\left.1^{\mathrm{a} e d .}\right)$ Loures: Lusodidacta; 2017: 227-251.

11. Fujino $\mathrm{Y}$, Amimoto $\mathrm{K}$, Fukata $\mathrm{K}$, Ishihara $\mathrm{S}$, Makita S, Takahashi $\mathrm{H}$. Does training sitting balance on a platform tilted $10^{\circ}$ to the weak side improve trunk control in the acute phase after stroke? A randomized, controlled trial. Top Stroke Rehabil. 2016 Jan 2;23(1):43-9.Doi: 10.1179/1945511915Y.0000000010.

12. Haruyama K, Kawakami M, Otsuka T. Effect of core stability training on trunk function, standing balance, and mobility in stroke patients: a randomized controlled trial. Neurorehabil Neural Repair. 2017 Mar;31(3):240-9.

13. Lupo A, Cinnera AM, Pucello A, Coiro P, Personeni S, Iolascon G, Paolucci S. Effects on balance skills and patient compliance of biofeedback training with inertial measurement units and exergaming in subacute stroke: a pilot randomized controlled trial. Funct Neurol. 2018 Jul 1;33(3):131-6.

14. Diário da República. Regulamento $.^{\circ} 392 / 2019$. Regulamento das Competências Comuns do Enfermeiro Especialista em Enfermagem de Reabilitação. Diário da República, $2^{\mathrm{a}}$ série $\mathrm{N}^{\circ} 85$. 2019, Maio 3: 13565-13568. [acedido a 13 de Maio de 2019]. Disponível em: https://www.ordemenfermeiros.pt/media/ 10778/0474404750.pdf.

15. Assembleia do Colégio da Especialidade de Enfermagem de Reabilitação. Padrão Documental dos Cuidados de Enfermagem da Especialidade de Enfermagem de Reabilitação. Porto: Ordem dos Enfermeiros; 2015 [acedido a 31 de Janeiro de 2019]. Disponível https://www.ordemenfermeiros.pt/arquivo/colegios/ Documents/2015/MCEER_Assembleia/PadraoDocumental_EER.pd f.

16. Andrade SR, Ruoff AB, Piccoli T, Schmitt MD, Ferreira A, Xavier AC. O Estudo De Caso Como Método De Pesquisa Em Enfermagem: Uma Revisão Integrativa. Texto Contexto Enferm [Internet], 20172015 [acedido a 13 de Maio de 2019]; 26(4):e5360016. Disponível em: http://dx.doi.org/10.1590/0104 07072017005360016.

17. Nunes L. Considerações éticas: a atender nos trabalhos de investigação académica de enfermagem. Setúbal: Departamento de Enfermagem ESS; 2013. [acedido a 30 de Julho 2019]. Disponível em: https://comum.rcaap.pt/bitstream/10400.26/4547/1/consid\%2 0eticas\%20na\%20investig\%20academica\%20em\%20enfermagem.p df.

18. Mesa do Colégio da Especialidade de Enfermagem de Reabilitação. Instrumentos de recolha de dados para a documentação dos cuidados de enfermagem de reabilitação. Ordem dos Enfermeiros; 2016. [acedido a 30 de Julho 2019]. Disponível em: https://www.ordemenfermeiros.pt/arquivo/colegios/Document s/2017/InstRecolhaDadosDocumentacaoCuidEnfReabilitacao_Fin al_2017.pdf.

19. Apóstolo, JLA, Instrumentos para Avaliação em Geriatria (Geriatric Instruments) Escola Superior de Enfermagem de Coimbra, 2012, Maio.

20. Direção-Geral da Saúde. Norma da Direção-Geral de Saúde $N^{\circ}$ 054/2011 - Acidente Vascular Cerebral: Prescrição de Medicina Física e Reabilitação. Direção-Geral de Saúde; Lisboa. 2011, Dezembro 27. [acedido a 30 de Julho 2019]. Disponível em: https://www.dgs.pt/directrizes-da-dgs/normas-e-circularesnormativas/norma-n-0542011-de-27122011-jpg.aspx

21. Meleis, Al. Transition Theory. Middle Range and Situation Specific Theories in Nursing Research and Practice. Springer Publishing Company Inc. New York; 2010. ISBN 978-0-8261-0534-9.

22. Santos B, Ramos A, Fonseca C. Da formação à prática: Importância das Teorias do Autocuidado no Processo de Enfermagem para a melhoria dos cuidados. Journal of Aging and Inovation. 2017 Abr; 6(1):51-54. ISSN: 2182-6951.

23. Kim HS, Kollak I. Nursing Theories. Conceptual \& Philosophical Foundations. Springer Publishing Company Inc. ( $2^{\mathrm{a}} \mathrm{ed}$.). New York; 2006. ISBN 0-8261-4005-X. 